\title{
Eskişehir Ekolojisinde Uygun Ekim Zamanı ve Ekim Sıklığının Yem Bezelyesinin Yaş Ot Verimi ve Bazı Özelliklerine Etkisi
}

\author{
Şule Erkovan $^{1} \quad$ Onur İleri $^{2} \quad$ Halil İbrahim Erkovan ${ }^{3^{*}} \quad$ Ali Koç $^{4}$ \\ ${ }^{1,2,3,4}$ Eskişehir Osmangazi Üniversitesi, Ziraat Fakültesi, Tarla Bitkileri Bölümü, Eskişehir \\ *Sorumlu yazar: erkovan@ogu.edu.tr \\ ${ }^{1}$ https://orcid.org/0000-0001-6235-6000, ${ }^{2}$ https://orcid.org/0000-0003-0728-4731, ${ }^{3}$ https://orcid.org/0000-0001-8511-0791, \\ ${ }^{4}$ https://orcid.org/0000-0001-5072-462x
}

Geliș Tarihi: 26.03.2020

Kabul Tarihi: 02.07.2020

$\ddot{\mathbf{O z}}$

Eskişehir ve benzer ekolojilerde kışlık ana ürün yem bezelyesi yetiştiriciliği potansiyelinin belirlenmesi amacıyla 2017-2018 ve 2018-2019 yıllarında yürütülen çalışmada iki farklı ekim zamanı ve üç ekim sıklığının iki yem bezelyesi çeşidinde bitki boyu, dal sayısı, yatma derecesi, yaş ot verimi ve kuru madde oranı incelenmiştir. İncelenen özellikler yönünden yıllar arasında çok önemli farklılıklar belirlenmiştir. Özkaynak ve Taşkent yem bezelyesi çeşitleri ile ekim zamanlarının incelenen özelliklere etkisi bulunmamıştır. Yem bezelyesinin ekim sıklığı yaş ot verimini \%1 seviyesinde etkilemiştir. Araştırma sonuçlarına göre bölgede yapılacak yem bezelyesi kışlık ana ürün yetiştiriciliğinde $\mathrm{m}^{2}$ ' de 80-100 tohum, sonbaharda Ekim veya Kasım aylarında ekim yapılmasının uygun olduğu ve çalışmada incelenen her iki çeşidin (Özkaynak ve Taşkent) de kullanılabileceği önerilmiştir.

Anahtar Kelimeler: Yem bezelyesi, ekim zamanı, ekim sıklı̆̆ı, yaş ot verimi

\section{The Effects of Sowing Date and Rate on Fresh Forage Yield and Some Characteristics of Forage Pea in Eskisehir Ecology \\ Abstract}

This research was carried out to determine the potential of forage pea as main winter crop for Eskisehir and similar ecology during 2017-2018 and 2018-2019 years. In the study, two different sowing dates and three various seeding rates were tested on two pea genotypes. Plant height, number of pods, tilting rate, fresh forage yield and dry matter ratio were examined. There were significant differences of years in terms of the examined characteristics. Ozkaynak and Taskent cultivars and sowing date did not affect significantly the examined characteristics. Sowing rate affected the fresh forage yield in 1,0\% significance level. Sowing in October or November using $80-100$ seeds $/ \mathrm{m}^{2}$ of Ozkaynak or Taskent cultivars could be suggested for main winter crop forage pea cultivation in the region.

Keywords: Forage pea, sowing date, sowing rate, fresh forage yield

\section{Giriş}

Ülkemiz iklim ve arazi yapısı bakımından oldukça farklı özelliklere sahiptir. Bu durum hem doğal bitki örtüsünde hem de tarımsal üretimde çeşitliliği etkilemektedir. Bitkisel üretimdeki çeşitlilik özellikle sulu tarım alanlarında kendini hissettirmektedir. Bu tür alanlarda vejetasyon periyodunun kısa olduğu yerlerde yüksek getirili endüstri bitkilerinde verim düşük olduğu için teşvikler sonrası yem bitkileri yetiştiriciliğine yöneliş artmıştır. Oysa nakit getirisi yüksek olan bitkilerin tatminkar verim verdiği daha uzun vejetasyon periyoduna sahip yerlerde çok yıllık yem bitkilerine rağbet azalmaktadır.

Eskişehir ovası orta uzunlukta bir yetişme mevsimine sahiptir ve başta şeker pancarı olmak üzere endüstriyel amaçlı bitkilerden tatminkar gelir elde edildiği için üreticiler tarım sisteminde yonca gibi çok yıllık yem bitkilerine yer vermede isteksiz davranmaktadır. Zira çok yıllık yem bitkileri ekonomik açıdan endüstriyel amaçlı bitkiler ile rekabet edememektedir (Ağırbaş ve ark. 2017). Diğer yandan Eskişehir yöresinde kayda değer bir hayvansal üretim söz konusu olup ciddi miktarda kaliteli kaba yem açığı söz konusudur. Bu açığın kapatılmasında hasat artıkları önemli rol oynamakta (Ağırbaş ve ark. 2017), buna ilaveten üreticiler kışlık ana ürün olarak yem bezelyesi veya ikinci ürün silaj mısır yetiştiriciliği gibi alternatif yolları aramaktadır. 
Tek yıllık baklagiller kışlık ara ürün veya ikinci ürün olarak ürün desenine dahil edilmesi durumunda yüksek getirili bitkilerin ekim alanı etkilenmeden ilave kazanç sağlamanın yanı sıra, kaliteli kaba yem üretiminin artırılması, arazinin etkin kullanımı ve takip eden bitkiler için avantaj sağlaması gibi faydaları da beraberinde getirecektir (Açıkgöz, 2001; Kavut ve Geren, 2015). Yem bezelyesi yörede yetişme mevsimi nedeniyle şeker pancarı öncesi iyi bir kışlık ara ürün olmasa da tane mısır veya silaj mısır ile biraz daha geç ekilen/dikilen bitkiler için kışlık ara ürün olarak önemli bir potansiyele sahiptir. Ancak bu bitki ne zaman ekilmelidir? Ne sıklıkta ekilmelidir? Sorularına cevap bulunması bu işin bilimsel esaslara uyumlu yürütülmesi açısından hayati öneme sahiptir.

Yem bezelyesi ülkemizin en soğuk bölgesi olan Doğu Anadolu Bölgesinde kışlık olarak yetiştirilebilmektedir (Tekeli ve Ateş, 2003; Tan ve ark. 2013). Ancak bitkinin kışa girmedeki gelişme aşaması kışa dayanıklılık açısından önemlidir. Çok erken ekilen aşırı büyüme, geç ekilenler ise yeterli büyüme gösteremediği için kıştan olumsuz etkilenmektedir. Bu nedenle güzlük ekim zamanı önemli bir konudur. Bu konuda yapılan çalışmalarda yörelere göre değişmekle birlikte güzlük ekim zamanının eylül-aralık ayları arasında değiştiğine dikkat çekilmiştir (Uzun ve Açıkgöz, 1998; Kadıŏlu ve Tan, 2018). Tipik bir serin mevsim yem bitkisi olan yem bezelyesi yüksek sıcaklardan olumsuz etkilendiği için yazlık ekimlerde kısa sürede gelişmesini tamamlamak zorunda kaldığından daha uzun serin dönemde gelişme şansı bulan güzlük ekimler kadar verimli olamamaktadır. Zira bezelye en iyi gelişme performansını 13-18 ${ }^{\circ} \mathrm{C}$ sıcaklık aralığında yapmaktadır (Sheaffer ve Moncada, 2012). Nitekim bu konuda yapılan çalışmalarda kışa dayanıklı çeşitlerin güzlük ekimlerinin yazlık ekimlerine göre daha uzun boylu oldukları ve yem üretiminin daha yüksek olduğu rapor edilmiştir (Shaukat ve ark. 2012; Mukherjee ve ark. 2013).

Yem bezelyesi ile yapılan çalışmalarda ekim sıklığının 60 ile $100 \mathrm{bitki} / \mathrm{m}^{2}$ arasında değiştiği kaydedilmektedir (Uzun ve Açıkgöz, 1998; Toğay ve ark. 2006; Uzun ve ark. 2017; Stepanovic ve ark. 2018). Bu konuda bitki habitusunun önemli olduğu kadar güzlük ekimlerde kıştan zarar görme durumu da etkili olmaktadır. Genel olarak kıştan zarar görme riski olan bitkilerin yazlık ekimlerine göre daha sık ekilmesi tavsiye edilmektedir.

Çok yıllık yem bitkilerinin ekim sisteminde fazla yer bulamadığı Eskişehir Ovasında kaliteli kaba yem açığını kapatmaya katkı sunabilmek amacıyla kışlık ara ürün olarak yöreye uyumlu ve kışa dayanıklı iki yem bezelyesi çeşidinde ekim zamanı ve sıklığının yeşil ot verimi ve bazı özelliklerine etkisinin belirlenmesi amaçlanmıştır.

\section{Materyal ve Yöntem}

Deneme 2017-2018 ve 2018-2019 yılları arasında Eskişehir Osmangazi Üniversitesi Ziraat Fakültesi Araştırma alanlarında yürütülmüştür. Deneme 2 yem bezelyesi çeşidi (Özkaynak ve Taşkent), sonbahar (Ekim ortası) ve geç sonbahar (Kasım ortası) olarak 2 ekim zamanı ile 3 farklı tohumluk miktarı $\left(80,100\right.$ ve 120 tohum $\left./ \mathrm{m}^{2}\right)$ ele alınmıştır. Deneme Tesadüf Blokları Deneme Desenine göre 3 tekerrürlü olarak yürütülmüştür. Denemede sonbahar ekimlerinin performanslarının tam olarak ortaya konulması için ilkbaharda ekimine yer verilmiş ancak ikinci yıl kuş zararı olduğu için ilkbahar ekimleri denemeden çıkarılmıştır. Ekimler $30 \mathrm{~cm}$ sıra arasına sahip $5 \mathrm{~m}$ uzunluğunda 5 sıradan oluşan parsellere markörle açılan çizgilere elle yapılmıştır. Gübre olarak $3 \mathrm{~kg} \mathrm{~N} / \mathrm{da}$ ve $7 \mathrm{~kg}$ $\mathrm{P}_{2} \mathrm{O}_{5} /$ da olacak şekilde Diamonyum Fosfat gübresi uygulanmıştır. Yabancı ot mücadelesi elle yapılmışıtır. Bitkiler kışa Ekim ayında yapılan ekimde 4-6, Kasım ayında yapılan ekimde ise 2-4 yapraklı olarak girmişlerdir.

Araştırmanın yürütüldüğ̈̈ yıllarda ortalama sıcaklık sırasıyla 12.2 ve $13.6{ }^{\circ} \mathrm{C}$ olup uzun yıllar ortalamasına yakın $\left(12.9{ }^{\circ} \mathrm{C}\right)$ seyretmiştir. Araştırmanın yürütüldüğü her iki kış döneminde de sıcaklıklar $-15^{\circ} \mathrm{C}$ 'ın altına düşmemiştir. Araştırmanın yürütüldüğü ilk yıl $440.8 \mathrm{~mm}$ yağış düşerken ikinci yılda $522.2 \mathrm{~mm}$ düşmüş ve uzun yıllar ortalamasından $(376.6 \mathrm{~mm})$ her iki yılda da daha yüksek olmuştur. Genel hatlarıyla ilk ürün yılı baharı daha 1lık ve yağışlı geçerken, ikinci ürün yılı daha serin fakat daha kurak geçmiştir (Çizelge 1). Araştırma sahasının toprakları killi tınlı bünyeye sahip olup, toprak pH's1 nötr veya nötre yakın (7.68), kireç içeriği \%14.61, tuzsuz, organik maddece fakir, potasyum $(168.8 \mathrm{~kg} \mathrm{~K} / \mathrm{da})$ bakımından zengin ve fosfor $\left(6.16 \mathrm{~kg}_{2} \mathrm{O}_{5} / \mathrm{da}\right)$ bakımından düşük seviyededir.

Alt baklaların dolduğu dönemde biçim yapılan denemede, biçimden önce yatma durumu 1-5 skalasına (1: yatık, 5: dik) göre tespit edilmiştir. Her parselde belirlenen 10 bitkide dal sayısı 
(adet/bitki) ve toprak seviyesinden bitkinin en uç noktası ölçülerek bitki boyu (cm) belirlenmiştir. Parsellerden biçilen bitkiler tartılmış ve dekara yaş ot verimleri hesaplanmıştır. Yaş ot verimini belirlemek üzere tartılan örneklerden 500 gram yaş ot örneği alınmış ve etüvde $105{ }^{\circ} \mathrm{C}$ sıcaklıkta kurutularak kuru madde oranları (\%) hesaplanmıştır. Deneme sonucunda elde edilen veriler varyans analizine tabi tutulmuş, ortalamalar Bonferroni/Dunn çoklu karşılaştırma testi ile karşılaştırılmışır (Sas Institute, 1998).

Çizelge 1. Ürün yılları ve uzun yıllar ortalamasına göre Eskişehir ili bazı iklim kayıtları.

\begin{tabular}{|l|c|c|c|c|c|c|c|c|c|c|c|c|}
\hline & \multicolumn{3}{|c|}{ Toplam Yağ1s $(\mathrm{mm})$} & \multicolumn{3}{c|}{ Ortalama Sicakl1k $\left({ }^{\circ} \mathrm{C}\right)$} & \multicolumn{3}{|c|}{ Ortalama Nispi Nem $(\%)$} \\
\hline Aylar & $\mathbf{2 0 1 7}$ & $\mathbf{2 0 1 8}$ & $\mathbf{2 0 1 9}$ & UYO & $\mathbf{2 0 1 7}$ & $\mathbf{2 0 1 8}$ & $\mathbf{2 0 1 9}$ & UYO & $\mathbf{2 0 1 7}$ & $\mathbf{2 0 1 8}$ & $\mathbf{2 0 1 9}$ & UYO \\
\hline Ocak & 28,3 & 31,5 & 60,2 & 38,7 & $-1,7$ & 2,2 & 4,3 & 0,3 & 99,3 & 95,5 & 91,0 & 98,2 \\
\hline Şubat & 8,8 & 40,5 & 50,1 & 32,5 & 2,8 & 6,6 & 3,4 & 4,7 & 92,2 & 90,7 & 79,6 & 92,6 \\
\hline Mart & 26,9 & 74,8 & 13,4 & 33,4 & 8,5 & 10,1 & 6,3 & 9,3 & 80,4 & 81,5 & 64,5 & 81,6 \\
\hline Nisan & 60,2 & 16,5 & 26,7 & 35,0 & 10,8 & 15,4 & 9,5 & 13,1 & 73,5 & 60,7 & 69,3 & 67,8 \\
\hline May1s & 101,0 & 84,8 & 42,2 & 44,8 & 15,4 & 17,6 & 16,5 & 16,5 & 83,4 & 83,0 & 65,1 & 86,1 \\
\hline Haziran & 49,3 & 72,5 & 45,7 & 30,6 & 20,1 & 20,6 & 20,9 & 20,4 & 85,3 & 80,7 & 67,9 & 83,3 \\
\hline Temmuz & 9,5 & 38,3 & 33,5 & 14,0 & 23,7 & 23 & 21,3 & 23,3 & 73,8 & 71,4 & 62,3 & 75,8 \\
\hline Ağustos & 29,9 & 25,0 & 2,4 & 7,8 & 22,4 & 23,5 & 22,3 & 22,9 & 60,2 & 62,2 & 61,0 & 74,1 \\
\hline Eylül & 6,8 & 4,3 & 5,0 & 14,4 & 20,9 & 19,1 & 18,1 & 20,0 & 58,3 & 62,9 & 62,1 & 68,1 \\
\hline Ekim & 52,7 & 41,0 & 18,3 & 27,0 & 11,9 & 14 & 14,2 & 12,9 & 78,3 & 75,5 & 70,1 & 79,6 \\
\hline Kasım & 33,4 & 29,6 & 33,9 & 29,2 & 6,7 & 8,4 & 7,9 & 7,5 & 86,9 & 79,2 & 76,2 & 80,3 \\
\hline Aralık & 34,0 & 63,6 & 74,1 & 45,1 & 4,5 & 2,7 & 2,9 & 3,6 & 92,5 & 96,0 & 89,9 & 93,6 \\
\hline Toplam/Ort. & $\mathbf{4 4 0 , 8}$ & $\mathbf{5 2 2 , 4}$ & $\mathbf{4 0 5 , 5}$ & $\mathbf{3 5 2 , 4}$ & $\mathbf{1 2 , 2}$ & $\mathbf{1 3 , 6}$ & $\mathbf{1 2 , 3}$ & $\mathbf{1 2 , 9}$ & $\mathbf{8 0 , 3}$ & $\mathbf{7 8 , 3}$ & $\mathbf{7 1 , 6}$ & $\mathbf{8 1 , 8}$ \\
\hline
\end{tabular}
Araştırma Bulguları ve Tartışma

Çizelge 2. Sonbaharda farklı ekim zamanı ve sıklıklarında ekilen yem bezelyesi çeşitlerine ait ortalamalar ve varyans analiz sonuçları

\begin{tabular}{|c|c|c|c|c|c|}
\hline $\begin{array}{c}\text { Uygulama / İncelenen } \\
\text { Özellikler }\end{array}$ & $\begin{array}{l}\text { Bitki Boyu } \\
(\mathrm{cm})\end{array}$ & $\begin{array}{c}\text { Dal } \\
\text { Say1s1 } \\
\end{array}$ & $\begin{array}{c}\text { Yatma } \\
\text { Derecesi }\end{array}$ & $\begin{array}{c}\text { Yaş Ot Verimi } \\
(\mathrm{kg} / \mathrm{da})\end{array}$ & $\begin{array}{c}\text { Kuru Madde } \\
\text { Oran1 }(\%)\end{array}$ \\
\hline & $122.58 \mathrm{~A}$ & $3.90 \mathrm{~B}$ & $4.00 \mathrm{~A}$ & $1812.74 \mathrm{~A}$ & $20.49 \mathrm{~B}$ \\
\hline Yil (Y) & $96.85 \mathrm{~A}$ & $7.11 \mathrm{~A}$ & $3.03 \mathrm{~B}$ & $1679.16 \mathrm{~B}$ & $26.08 \mathrm{~A}$ \\
\hline & 109.71 & 5.62 & 3.50 & 1730.52 & 22.92 \\
\hline Taşkent & 109.72 & 5.39 & 3.53 & 1761.38 & 23.65 \\
\hline & 112.81 & 5.39 & 3.64 & 1724.03 & 23.45 \\
\hline Zamanı (EZ) & 106.62 & 5.62 & 3.39 & 1767.87 & 23.12 \\
\hline \multirow{2}{*}{$\begin{array}{l}\text { Ekim S1klığ } 1 \\
\quad(\mathrm{ES})\end{array}$} & 108.89 & 5.33 & 3.58 & $1796.88 \mathrm{~A}$ & 23.44 \\
\hline & 111.53 & 5.71 & 3.54 & $1847.77 \mathrm{~A}$ & 23.50 \\
\hline 120 tohum $/ \mathrm{m}^{2}$ & 108.73 & 5.48 & 3.43 & $1593.21 \mathrm{~B}$ & 22.92 \\
\hline Ortalama & 109.72 & 5.51 & 3.52 & 1745.95 & 23.29 \\
\hline ( & $* *$ & $* *$ & $* *$ & $*$ & $* *$ \\
\hline Ç & öd & öd & öd & öd & öd \\
\hline $\mathrm{EZ}$ & öd & öd & öd & öd & öd \\
\hline ES & öd & öd & öd & $* *$ & öd \\
\hline Y x C & öd & öd & öd & $*$ & öd \\
\hline $\mathrm{Y} \times \mathrm{EZ}$ & öd & öd & $* *$ & öd & $* *$ \\
\hline Yx ES & öd & öd & öd & $* *$ & öd \\
\hline Ç x EZ & öd & $*$ & öd & $* *$ & $* *$ \\
\hline $\mathrm{C} \times \mathrm{ES}$ & öd & öd & öd & $* *$ & öd \\
\hline $\mathrm{EZ} \times \mathrm{ES}$ & öd & öd & öd & $* *$ & öd \\
\hline$Y \times C ̧ \times E Z$ & öd & öd & öd & öd & $*$ \\
\hline Y x C x ES & öd & öd & öd & öd & öd \\
\hline$Y \times E Z \times E S$ & öd & öd & öd & $* *$ & öd \\
\hline C x EZx ES & öd & öd & öd & $* *$ & öd \\
\hline$Y \times C ̧ \times E Z \times E S$ & öd & öd & öd & $* *$ & öd \\
\hline
\end{tabular}


Yıllar arasındaki farklılık dışında uygulamalar ve uygulamalar arasındaki interaksiyonlar önemsiz bulunmuştur (Çizelge 2). Ortalama bitki boyu $109.72 \mathrm{~cm}$ olup, 2018 y1lında $122.58 \mathrm{~cm}, 2019$ y1lında $96.85 \mathrm{~cm}$ olarak kaydedilmiştir (Çizelge 2).

İncelenen özelliklerden dal sayısı bitki boyuna benzer olarak yıllara göre önemli farklılık $(\mathrm{p}<0.001)$ göstermiştir (Çizelge 2). İlk y1l 3.90 olan bitki başına dal sayısı, ikinci yılda 7.11 olarak belirlenmiştir. Ele alınan yem bezelyesi çeşitlerinin bitki başına dal sayısı yönünden ekim zamanına tepkisi farklı olmuştur. Ekim ayında yapılan ekimde Taşkent çeşidi, kasım ayında yapılan ekimde ise Özkaynak çeşidi diğerine göre daha fazla dal sayısına sahip olmuştur (Şekil 1). Çeşitler arasında ortaya çıan bu farklılık çeşit $\mathrm{x}$ ekim zamanı interaksiyonunun önemli $(\mathrm{p}<0.05)$ çıkmasına sebep olmuştur. Diğer interaksiyonlar ise önem sergilememiştir (Çizelge 2).

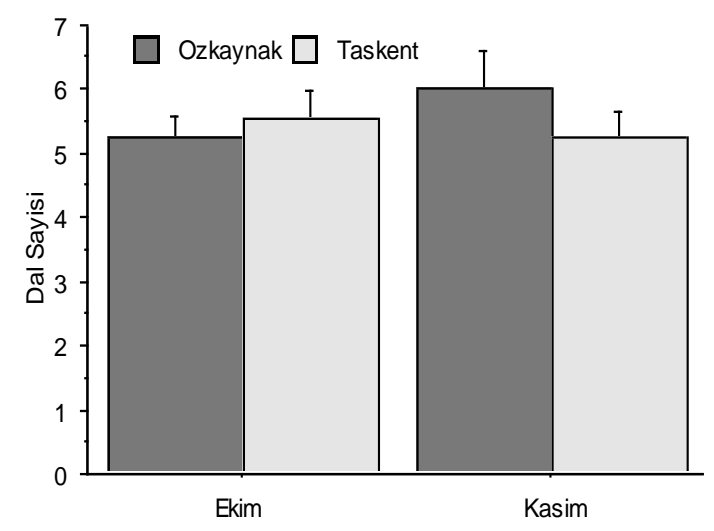

Şekil 1. Sonbaharda farklı ekim zamanı ve sıklıklarında ekilen yem bezelyesinde dal sayısına ait çeşit x ekim zamanı interaksiyonu

Yatma oranı yıllar arasında önemli farklılık $(\mathrm{p}<0.001)$ göstermiş olup ikinci yılda yatma oranı daha yüksek olmuştur (Çizelge 2). Yem bezelyesinin ekim zamanına göre yatma derecesi yıllara bağlı olarak değişim sergilemiştir. Ekim döneminde yapılan ekimde 2017 yılında daha dik gelişen bitkiler, Kasım ayında yapılan ekimde yıllar arasında önemli bir farklılık göstermemiş benzer yatma derecesine sahip olmuştur. Yatma derecesinde ekim zamanına bağlı olarak yıllar arasında ortaya çıkan bu farklılık yıl x ekim zamanı interaksiyonunun önemli çıkmasında etkili olmuştur (Şekil 2).

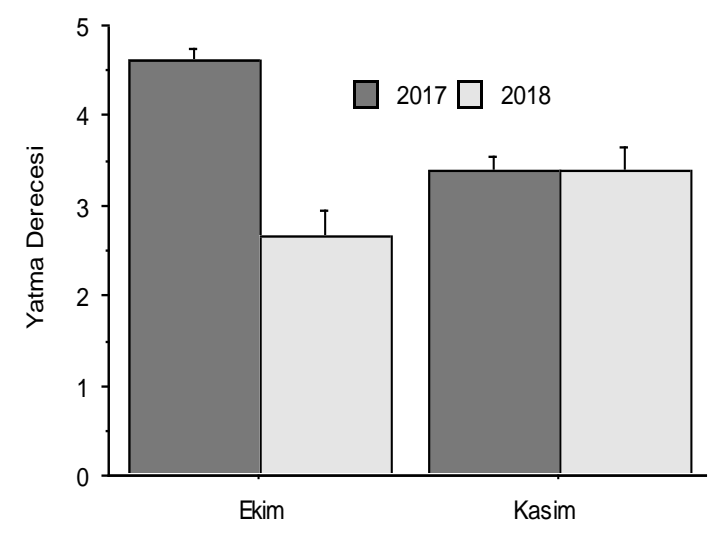

Şekil 2. Sonbaharda farklı ekim zamanı ve sıklıklarında ekilen yem bezelyesinde yatma derecesine ait yıl x ekim zamanı interaksiyonu

Yaş ot verimi 2018 y1lında $1812.74 \mathrm{~kg} / \mathrm{da}, 2019$ yılında $1679.17 \mathrm{~kg} / \mathrm{da}$ olarak kaydedilmiştir. Yıllar arasında ortaya çıkan bu farklılık \%5 düzeyinde önemli olmuştur (Çizelge 2). Çeşit ve ekim zamanının yaş ot verimi üzerine etkisi istatistiki olarak önemli olmamıştır.

İlk yıl elde edilen yaş ot verimi ikinci yıl elde edilene göre daha yüksek olmuştur. En yüksek ekim sıklığında yaş ot verimi diğer iki ekim sıklığına göre daha düşük olmuştur (Çizelge 2). Yıllar, çeşitler, ekim zamanı ve ekim sıklığının yaş ot verimi üzerine birlikte etkisi farklı şekillerde önemli olmuş ve bunun sonucunda yıl x çeşit, yıl x ekim sıklığ ekim zamanı x ekim sıklığı, yıl x ekim zamanı x ekim sıklığı, çeşit x ekim zamanı x ekim sıklığı ile yıl 
x çeşit x ekim zamanı x ekim sıklığı interaksiyonların önemli çıkmıştır. Ancak ortaya çıkan bu etkileşimler istikrarlı bir değişim sergilememiştir (Şekil 3).

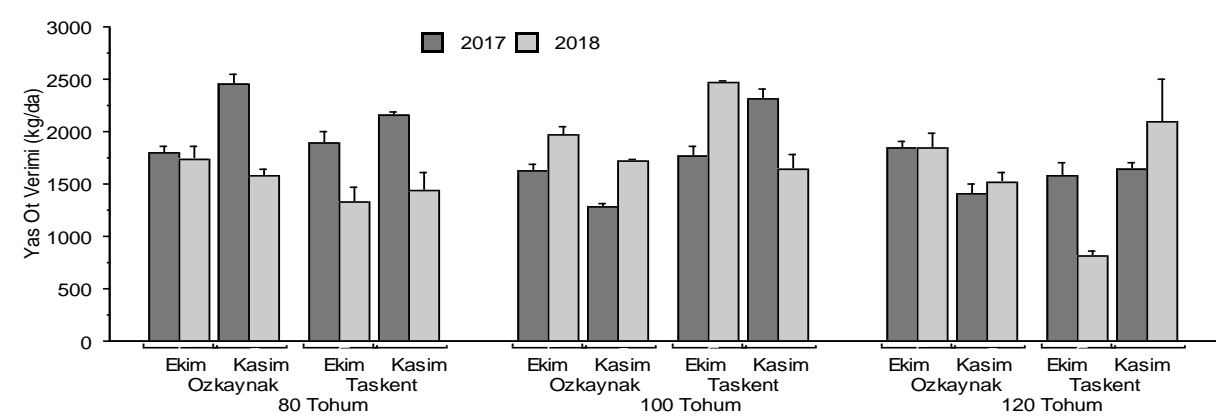

Şekil 3. Sonbaharda farklı ekim zamanı ve sıklıklarında ekilen yem bezelyesinde yaş ot verimine ait yıl x çeşit x ekim zamanı x ekim sıklı̆g interaksiyonları

Sonbaharda farklı ekim zamanı ve sıklıklarında ekilen yem bezelyesi çeşitlerinin kuru madde oranları yıllara göre önemli farkl1lık ( $\mathrm{p}<0.001$ ) göstermiş olup, 2018 yılında $\% 20.49$ olan kuru madde oranı 2019 yllında \%26.08 olarak belirlenmiştir (Çizelge 2). Kuru madde oranı üzerine çeşit, ekim zamanı ve ekim sıklığının etkisi önemsiz olmuştur. Kuru madde oranı bakımından çeşitlerin, ekim zamanı ve yıllara göre tepkisi farklı olmuş (Şekil 4) ve bunun bir sonucu olarak yıl x ekim zamanı, çeşit x ekim zamanı ve yıl x çeşit x ekim zamanı interaksiyonları önemli olmuştur.

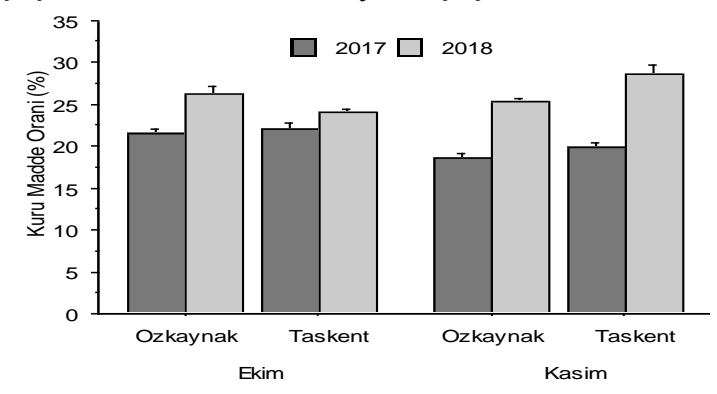

Şekil 4. Sonbaharda farklı ekim zamanı ve sıklıklarında ekilen yem bezelyesinde kuru madde oranlarına ait yıl $\mathrm{x}$ çeşit x ekim zamanı interaksiyonu

Yem bezelyesi serin iklim yem bitkisi olup erken ilkbaharın serin ve nemin problem olmadığı, ortalama sıcaklığın 13-18 ${ }^{\circ} \mathrm{C}$ arasında değiştiği dönemde en iyi gelişme performansını sergilemektedir (Sheaffer ve Moncada, 2012). Dolayısıyla serin ve nemli büyüme döneminin uzunluğu bitki gelişimini olumlu yönde etkilemektedir (Tan ve ark. 2011; Uzun ve ark. 2012). Her ne kadar denemenin ilk yıl1 ikinci yıla göre daha sıcak olsa da şubat, mart ve mayıs aylarında uzun yıllar ortalamasına göre daha fazla yağış düşmüş ve bu durum bitki gelişmesini olumlu yönde etkilediği için ilk ürün yıllnda daha uzun boylu bitkiler elde edilmiştir. İkinci ürün yılının baharı daha serin geçmesine rağmen uzun yıllar ortalamasının altında yağı̧̧ düşmesi bitkilerde su stresini tetiklediği için bitkiler daha kısa boylu olmuşlardır. Zira su stresi bitkilerde büyümeyi kısıtlayarak generatif devreye geçişi teşvik etmektedir (Wissuwa ve ark. 1997; Yokota ve ark. 2006; Quan ve ark. 2016; Özel ve ark. 2016). Bunun bir sonucu olarak da bitkilerin kısa kalması beklenen bir durumdur. Benzer sonuçlar Shaukat ve ark. (2012) ve Mukherjee ve ark. (2013) tarafından da kaydedilmiştir. Ele alınan iki çeşitte yörede yapılan uyum denemelerinde yöreye iyi uyum sağladığı ve benzer performans sergiledikleri kaydedilmiştir (Dereli, 2015). Nitekim bu çalışmada da bitki boyu yönünden uygulamalara benzer tepki göstermişler ve aralarında önemli bir farklılık bulunamamıştır (Çizelge 2). Bitki boyu üzerine ekim sıklıklarının etkisinin önemsiz olması, ekim sıklığının rekabet gücünü etkileyecek seviyelerde olmamasından kaynaklanmış olabilir. Nitekim Türk ve ark. (2011) yürüttükleri çalışmada ekim sıklıkları bitki boyunu etkilemediği yönündeki bulguları da bu ifadeyi desteklemektedir. 
Yem bezelyesinde ana dal sayısı yıllara göre farklılık göstermiş, 2019 yılında dal sayısı daha fazla bulunmuştur. Bitkilerde dallanma genetik yapı ve çevre faktörlerinin etkisi altında şekillenmektedir (Ceyhan, 2003). Yüksek sicaklılar bitkilerde dallanma üzerine olumsuz etkide bulunmaktadır (Manga, 1977). Nitekim bu çalışmada da ilkbaharda havaların mart ve nisan aylarında uzun yıllar ortalamasına göre daha sıcak geçtiği 2018 yılında bitkilerde ana dal sayısı daha düşük olmuştur. Çeşit, ekim zamanı ve ekim sıklığı dal sayısını etkilemezken, çeşitlerin ekim zamanına karşı göstermiş olduğu tepkinin farklılığı nedeniyle çeşit x ekim zamanı interaksiyonu önemli bulunmuştur. Nitekim ülkemizde yürütülen çalışmalarda da ekim zamanına bağlı olarak dal sayılarının farklı olduğu ifade edilmiştir (Geren ve Alan, 2012). Bu durum çeşitlerin gelişme seyri ve diğer özellikler yönünden çevreye farklı tepki göstermesinden kaynaklanmıştır. Nitekim ilkbaharda havaların erken isındığı dönemde her iki çeşitte çevreye benzer tepki gösterirken, uzun yıllar ortalamasına benzer seyir izleyen 2019 yılında Özkaynak çeşidi daha fazla dallanmıştır. Taşkent çeşidi ise her iki yıla da benzer tepki göstermiştir. Bu durum Taşkent çeşidinin dallanma yönünden çevre faktörlerinden daha az etkilendiği şeklinde yorumlanabilir.

Yem bezelyesi yetiştiriciliğinde yatma önemli bir sorundur ve bitki boyu ile yakından ilişkilidir (Bilgili ve ark. 2007). Uzun boylu bitkiler yatmaya karşı daha hassastır. Ancak yatma salt bitki boyu ile ilgili olmayıp, gelişme çă̆ı, rüzgar ve yağış gibi çevre faktörleri (Taran ve ark. 2003) ile yakından ilişkilidir. İkinci ürün yılında bitkilerin kısa boylu olmasına rağmen daha fazla yatması gelişmenin ilerleyen dönemlerinde ortaya çıkan yağış ve rüzgar ile ilişkili olması muhtemeldir. Ele alınan çeşitler arasında yatma skoru yönünden farklılık olmayışı genetik yapıları ile ilgili bir durumdur. Nitekim bu çeşitlerin tescil aşamasındaki denemelerinde de yatma skoru yönünden farklı olmadığı rapor edilmiştir. (Anonim, 2018). Ekim zamanının ele alınan materyalin yatma derecesi üzerine istatistiki olarak bir etkisi olmamıştır. Bu durum ekimlerin güzlük olması ve ilkbaharda benzer bir gelişme seyri sergilemeleri ile ilgili olabilir. Ekim sıklıklarının yatma derecesi üzerine etkili olmayışı ele alınan sıklık değerlerinin bitkilerde ciddi bir rekabet ortaya çıkarmaması ile ilgili olabilir. Nitekim Kurşun Kırc1 (2012) Erzurum'da yürüttüğü çalışmada benzer sonuçlara dikkat çekmiştir. Denemede 2018 yılında ekim ayında ekilen parsellerde diğerine göre ve bir önceki yılın ekim ayı ekimine göre daha fazla yatma gerçekleşmiştir. Yıl x ekim zamanı interaksiyonuna sebep olan bu durum muhtemelen çevre faktörlerinin etkisinin ikinci yılda ekim zamanı üzerinden etkili olmasının bir sonucu olabilir.

Yem bezelyesi en iyi büyümeyi serin havalarda (ortalama sıcaklığın $13-18{ }^{\circ} \mathrm{C}$ olduğu dönemde) gerçekleştirir (Geisler, 1983; Sheaffer ve Moncada, 2012). Dolayısıyla denemenin ilk ürün yılında bahar ayları ikinci ürün yılına göre daha 1lık ve yağışlı geçmesi (Çizelge 1) nedeniyle ilk ürün yılında daha yüksek yeşil ot verimi elde edilmiştir. Çeşitler arasında farklılığın olmaması ele alınan iki çeşidin de benzer genetik potansiyele sahip olmasından kaynaklanması muhtemeldir. Kışları soğuk geçen yörelerde bitkiler kışı geçirdikten sonra ilkbahar döneminde aktif büyüme sergilediği ve her iki ekim zamanında da kış zararı gözlenmediği için benzer performans sergilemeleri beklenen bir durumdur. Nitekim kışları serin geçen yörelerde güzlük ekimlerde ekim tarihinin verim üzerine belirgin etkisi gözükmezken (Mukherjee ve ark. 2013), kışları büyümenin görüldüğü 1lıman yörelerde ise güzlük ekim zamanının etkisi belirgin olmaktadır (Soya ve ark. 1989; Sirwaiya ve Kushwah, 2018). Bitkilerde aşırı seyrek ve sık ekimler verimi olumsuz yönde etkilemektedir (Kavut ve ark. 2016; Toğay ve ark. 2006). Nitekim bu çalışmada da 80 ve 100 tohum $\mathrm{m}^{-2}$ ekimlerinde 120 tohum m $\mathrm{m}^{-2}$ ekimlerine göre daha yüksek verim alınmıştır. Bu sonuçlar kış zararının ciddi olmadığı yörelerde yem bezelyesinin 80-100 tohum $\mathrm{m}^{-2}$ sıklığında ekilmesinin uygunluğunu dikkat çekmektedir. Kurşun Kırcı (2012)'nin optimum sıklığın üzerinde yapılan ekimlerde yem bezelyesinde verimin düştügüne dikkat çekmesi bu ifadeyi desteklemektedir. Yıllar arasında iklimin seyrindeki değişme bağlı olarak yaş ot verimi yönünden yıl kaynaklı interaksiyonların çoğu önemli çıkmıştır. Verim genetik yapı ve çevrenin ortaklaşa bir ürünüdür (Biarnes-Dumoulin ve ark. 1996; Açıkgöz ve ark. 2009; Tolessa ve ark. 2013). Dolayısıyla bu tür interaksiyonlar beklenen bir durumdur. Ancak istatistiki olarak önemli olan bu etkileşimler yaş ot veriminde aşırı farklılıklara neden olmamış ve ekim zamanında takip eden yılda iklimin nasıl seyredeceği sağlıklı bir şekilde tahmin edilemediğinden interaksiyonlara bağlı öneri de isabetli olmayabilir.

Kuru madde oranı üzerine yılların önemli etkisi olmuştur. Araştırmanın ikinci yılında kuru madde oranı yüksek olmuştur. $\mathrm{Bu}$ durum ikinci yılın nispeten kurak geçmiş olmasından 
kaynaklanması muhtemeldir. Zira kuraklık bitkilerde su kaybını artırarak erken olgunlaşmayı teşvik eder (Kaiser, 1987; Özel ve ark. 2016). Bu durumda bitkilerde kuru madde oranının yüksek olması beklenen bir durumdur. Çeşit, ekim zamanı ve ekim sıklığının kuru madde oranı üzerine etkisi önemsiz bulunmuştur. Bu durum çeşitler arasında ciddi bir farklılık olmaması ve bitkilerin kuru madde içeriğinin ilkbaharda büyüme sürecinde etkili olan faktörler tarafından daha sıkı etkilendiği şeklinde yorumlanabilir. Kuru madde oranı bakımından yıl, çeşit ve ekim zamanı ikili ve üçlü interaksiyonlarının önemli çıkmasında temel belirleyici faktörün çevre olduğu şeklinde değerlendirilebilir.

Sonuç olarak Eskişehir ve benzer ekolojilerde takip eden y1lda geç ekilmesi planlanan her hangi bir çapa bitkisi öncesinde bir önceki ürünün tarlayı terk etmesine bakılmaksızın kışlık ara ürün olarak yem bezelyesinin yetiştirilebileceğini ifade etmemiz mümkündür. Bu amaçla Özkaynak veya Taşkent yem bezelyesi çeşitleri 80-100 tohum $\mathrm{m}^{-2}$ ekim sıklığında sonbaharda ekim ayının ikinci yarısı ile kasımın ilk yarısında ekilebilir. Ancak daha erken veya daha geç ekimler için yeni araştırmalara ihtiyaç vardır.

\section{Kaynaklar}

Açıkgöz, E. 2001. Yem Bitkileri. III. Baskı, U.Ü. Güçlendirme Vakfı Yay. No: 182. 584 s. Bursa.

Açıkgöz, E., Üstün, A., Gül, I., Anlarsal, E., Tekeli, A.S., Nizam, I., Avcıoglu, R., Geren, H., Cakmakci, S., Aydınoğlu, B., Yücel, C., Avcı, M., Acar, Z., Ayan, İ., Uzun, A., Bilgili, U., Sincik, M., Yavuz, M., 2009. Genotype $x$ environment interaction and stability analysis for dry matter and seed yield in field pea (Pisum sativum L.). Spanish Journal of Agricultural Research. 7: 96-106.

Ağırbaş, N.C., K. Sapmaz, A. Koç, 2017. Eskişehir ilinde yem bitkileri ekiliş alanı ve üretim miktarı üzerine tarımsal desteklemelerin etkisi. Atatürk Üniversitesi Ziraat Fakültesi Dergisi. 48: 65-72.

Anonim, 2018. Yem Bezelyesi-1 Tescil Raporu, Tarım ve Orman Bakanlığı Tohumluk Tescil ve Sertifikasyon Merkez Müdürlüğü, Ankara.

Biarnes-Dumoulin, V., Denis, J.B., Lejeune-Heanut, I., Eteve, G., 1996. Interpreting yield instability in pea using genotypic and environmental covariates. Crop Science. 36: 115-120.

Bilgili, U., Uzun, A., Sincik, M., Yavuz, M., Gül, İ., 2007. Farklı yaprak tiplerindeki yemlik bezelye hatlarının verim ve bazı verim özelliklerinin belirlenmesi, Türkiye VII. Tarla Bitkileri Kongresi. Bildiriler 2: Çayır Mera Yem Bitkileri ve Endüstri Bitkileri. 83-86. 25-27 Haziran, Erzurum.

Ceyhan, E., 2003. Bezelye ebeveyn ve melezlerinde bazı tarımsal özelliklerin ve kalıtımlarının çoklu dizi analiz metoduyla belirlenmesi. Selçuk Üniversitesi, Fen Bilimleri Enstitüsü, Doktora Tezi. 103 s.

Dereli, D.N., 2015. Eskişehir ekolojisinde bazı baklagil yem bitkilerinin ikinci ürün olarak yetiştirilebilirliği. Eskişehir Osmangazi Üniversitesi, Fen Bilimleri Enstitüsü, Yüksek Lisans Tezi. 58 s.

Geisler, G. 1983. Ertragsphysiologie von kulturarten des gemäßigten klimas. Paul Parey, Berlin, Hamburg.

Geren, H., Alan, Ö., 2012. Farklı ekim zamanlarının iki bezelye (Pisum sativum L.) çeşidinde ot verimi ve diğer bazı özellikler üzerine etkileri. ANADOLU Ege Tarımsal Araştırma Enstitüsü Dergisi. 22: 37-47.

Kadıoğlu, S., Tan, M., 2018. Erzurum şartlarında farklı tarihlerde kışlık ekilen yem bezelyesi çeşitlerinin verim ve bazı özellikleri. Tarla Bitkileri Merkez Araştırma Enstitüsü Dergisi. 27: 25-32.

Kaiser, W.M., 1987. Effects of water deficit on photosynthetic capacity. Physiologia Plantarum. 71: 142-149.

Kavut, Y.T., Çelen, A.E., Çıbık, Ş.E., Urtekin, M.A., 2016. Ege Bölgesi koşullarında farklı sıra arası mesafelerinde yetiştirilen bazı yem bezelyesi (Pisum arvense L). çeşitlerinin verim ve diğer bazı özellikleri üzerine bir araştırma. Tarla Bitkileri Merkez Araştırma Enstitüsü Dergisi. 25 (Özel Sayı-2): 225-229.

Kavut, Y.T., Geren, H., 1015. Farklı ön bitki ve ekim zamanı uygulamalarının silajlık mısırın (Zea mays L.) verim ve bazı kalite özelliklerine etkileri. Türk Tarım ve Doğa Bilimleri Dergisi. 2: 163-170.

Kurşun Kırcı, K., 2012. Doğu Anadolu yem bezelyesi ekotiplerinde tohum miktarı ve sıra aralığının ot ve tohum verimine etkileri. Atatürk Üniversitesi, Fen Bilimleri Enstitüsü, Yüksek Lisans Tezi. 53 s.

Manga, İ., 1977. Değişik gün uzunluğu ve sıcaklık derecelerinin korunganın gövde ve kök gelişmesine etkileri. Atatürk Üniversitesi Ziraat Fakültesi Dergisi. 8: 1-21.

Mukherjee, D., Sharma, B.R., Mani, J.K., 2013. Influence of different sowing dates and cultivars on growth, yield and disease incidence in garden pea (Pisum sativum) under mid hill stuation. Indian Journal of Agricultural Sciences. 83: 918-923.

Özel, S.D., Gökkuş, A., Alatürk, F., 2016. Farklı sulama seviyelerinin Macar fiği (Vicia pannonica Crantz.) ve yem bezelyesi (Pisum arvense L.) gelişimine etkileri. Alınteri Zirai Bilimler Dergisi. 30: 46-52.

Quan, W., Liu X., Wang H. and Chan Z., 2016. Comparative physiological and transcriptional analyses of two contrasting drought tolerant alfalfa varieties. Frontiers in Plant Science. 6: 1-16.

SAS Institute. 1998. Statistical Analysis System Institute: StatView Reference Manual. SAS Institute, Cary, NC. 
Shaukat, S.A., Ahmad, Z., Chodry, Y.A., Shaukat, S.K., 2012. Effect of different sowing dates and row spacing on then growth, seed yield and quality of off-season pea (Pisum sativum L. cv. Climax) under temperate conditions of Rawalakot Azad Jammu and Kashmir. Scientific Journal of Agricultural. 1: 117-125.

Sheaffer, C.C., Moncada, K.M. 2012. Introduction to Agronomy - Food, Crops and Environment. 2nd ed. 704 p. Delmar, Clifton Park, NY.

Sirwaiya, S., Kushwah, S.S., 2018. Assessment of different sowing dates and varieties on growth, yield and quality of seed in garden pea (Pisum sativum L.), International Journal of Current Microbiology and Applied Sciences. 7: 1387-1396.

Soya, H., Çelen A.E., Tosun, M., 1989. Sıra arası mesafesi ve ekim zamanının yem bezelyesi (Pisum arvense L.)'nde saman verimi ve verim özelliklerine etkisi. Ege Üniversitesi Ziraat Fakültesi Dergisi. 26: 11-21.

Stepanovic, S.V., Burr, C., Peterson, J.A., Rudnick, D., Creech, C.F. Werle, R., 2018. Field pea response to seeding rate, depth, and inoculant in West-Central Nebraska. Agronomy Journal. 110: 1412-1419.

Tan, M., Koç, A., Dumlu Gül, Z., Elkoca, E., Gül, İ., 2013. Determination of dry matter yield and yield components of local forage pea (Pisum sativum spp. arvense L.) ecotypes. Journal of Agricultural Sciences. 19: 289-296.

Taran, B., Warkentin, T., Somers, D.J., Miranda, D., Vanderberg, A., Blade, S., Woods, S., Bing, D., Xue, A., DeKoeyer, D., Penner, G., 2003. Quantitative traitloci for lodging resistance, plant height and partial resistance to Mycosphaerella blight in field pea (Pisum sativum L.). Theoretical and Applied Genetics. 107: 1482-1491.

Tekeli, A.S., Ates, E., 2003. Yield and its components in field pea (Pisum arvense L.) lines. Journal of Central European Agriculture. 4: 313-317.

Toğay, N., Toğay, Y., Erman, M., Yıldırım, B., 2006. Kışlık iki bezelye hattı (Pisum sativum ssp. arvense L.)'nda farklı bitki sıklıklarının bazı tarımsal özellikler üzerine etkisi. Yüzüncü Yıl Üniversitesi Ziraat Fakültesi Tarım Bilimleri Dergisi. 16: 97-103.

Tolessa, T.T., Keneni, G., Sefera, T., Jarso, M., Bekele, Y., 2013. Genotype x environment interaction and performance stability for grain yields in field pea (Pisum sativum L.) genotypes. International Journal of Plant Breeding. 7: 116-123.

Turk, M., Albayrak, S., Yuksel, O., 2011. Effect of seeding rate on the forage yields and quality in pea cultivars of differing leaf types. Turkish Journal of Field Crops. 16: 137-143.

Uzun, A., Acikgoz, E., 1998. Effect of sowing season and seedling rate on the morphological traits and yield in pea cultivars of differing leaf types. Journal of Agronomy and Crop Science. 181: 215-222.

Uzun, A., Asik, B.B., Acikgoz, E., 2017. Effects of different seeding rates on forage yield and quality components of pea cultivars under Bursa conditions. Turkish Journal of Field Crops. 22: 126-133.

Wissua, M. and Smith S.E., 1997. Morphological and physiological characteristic associated with tolerance to summer irrigation termination in alfalfa. Crop Science. 37: 704-711.

Yokota, A., Takahara, K., Akash, K., 2006. Water Stress. Physiology and Molecular Biology of Stress Tolerance in Plants. Springer Publ. 15-39 pp. Netherland. 